\title{
Video on Mobile Phones as an Effective Way to Promote Sustainable Practices by Facilitating Innovation Uptake in Mali
}

\author{
Fernando Sousa ${ }^{*}$, Gian Nicolay, Robert Home \\ FiBL - Research Institute of Organic Agriculture, Frick, Switzerland
}

Email address:

fernando.sousa@fibl.org (F. Sousa)

${ }^{*}$ Corresponding author

\section{To cite this article:}

Fernando Sousa, Gian Nicolay, Robert Home. Video on Mobile Phones as an Effective Way to Promote Sustainable Practices by Facilitating Innovation Uptake in Mali. International Journal of Sustainable Development Research. Vol. 5, No. 1, 2019, pp. 1-8.

doi: $10.11648 /$ j.ijsdr.20190501.11

Received: December 5, 2018; Accepted: December 25, 2018; Published: February 22, 2019

\begin{abstract}
A challenge for researchers and other developers of new technologies in agriculture is to find ways of communicating their results and recommendations. This challenge is particularly acute in regions in which farmers have limited access to education and where illiteracy is widespread, such as in the rural areas of Mali. One approach that shows potential, yet remains largely unused by extension services, is the dissemination of educational videos on mobile phones with video and Bluetooth technology (3G mobile phones). It has been shown that the conditions are suitable for this approach to be used in Mali, with $3 \mathrm{G}$ mobile phones widely available in the region but there is little empirical evidence of its acceptance and potential impact. This article aims to explore the potential of video on mobile phones as a tool to facilitate the diffusion of new agricultural technologies in Western Africa. Three videos showing agricultural innovations for sustainable production were shown and shared with 200 farmers in twelve villages in Mali. The villages were revisited 10 months later and farmers were asked about their experiences with the videos that had been shared and their previous knowledge of the innovations shown in them. Of the farmers who had watched one of the videos ( $\mathrm{N}=148), 60.1 \%$ had adopted at least one of the videos' innovations. Mobile-phone videos could be accessed by people who had previously received limited access to information sources, such as younger women, and video based information was found to be understandable for illiterate farmers. These results show that mobile-phone videos could enhance information transfer and thereby expand outreach. The use of video on mobile phones is a novel approach to farmer-to-farmer exchange and has tremendous potential for enhancing dissemination programs or specific research and development projects to enable more resilient, inclusive and democratic systems.
\end{abstract}

Keywords: Information and Communication Technology, Mobile Phone, Video, Agriculture Development, Farmer-to-Farmer Exchange

\section{Introduction}

Appropriate access to agricultural information is a central aspect of technology adoption and the development of the agricultural sector, with particular relevance for smallholder farmers in developing countries [1]. However, despite growing availability of information technologies in developing agricultural contexts [2, 3] and their longstanding promise as tools of facilitation of innovation diffusion [4], a significant proportion of farmers remain excluded from valuable agricultural information sources [5].
According to Rogers [6], one reason why there is so much interest in the diffusion of innovations is because getting a new idea adopted, even if it has obvious benefits, is often a very difficult and lengthy process. However, Ghadim and Panell [7] note that the nature of adoption decisions is dynamic and variable and emphasize the role of learning by doing and the impact of that learning on personal perceptions of the innovation. The technology acceptance model [8] suggests that new technologies will be adopted if they are perceived to be both useful and usable. The technology acceptance model was formulated to explain technology 
adoption across a broad range of innovation types, but it has not yet been investigated in the context of adoption of agricultural innovations: in other words whether agricultural innovations can be considered to be new technologies. Researchers in the field of agriculture must be in tune with the needs and demands of farmers, and convince them of tangible benefits, if they wish to see innovations resulting from their research findings widely adopted [9]. The implication of this is that there are two steps in the process of encouraging adoption of innovations. Firstly the innovations themselves must be perceived to be useful and usable in the intended context. Secondly, their use and usability must be communicated in a way that is understandable in the specific context so that it is able to convince the farmers of the benefits.

The aims of this article are to identify the conditions that enable adoption of agricultural innovations and to investigate whether the technology acceptance model can be applied to encourage adoption of innovations. More concretely, this study aims at measuring the extent to which mobile phone videos are able to facilitate the diffusion of agricultural innovations in a rural context in West Africa. Given that application of the technology acceptance model is context specific, these aims are addressed in the context of rural Mali in western Africa. The existing literature is first examined in order to find a context-appropriate means of information transfer. Once an appropriate means of information transfer has been identified, it is determined whether innovations are actually implemented after they have been communicated. The logic follows the argument that, if innovations have been implemented, both the first condition: that the farmers perceived them to be useful and usable; and the second condition: that the farmers have learned of the innovations, must have been met.

Facilitating agricultural innovation uptake through the use of IT.

After decades of policy interventions to promote agricultural technology adoption, it became evident that this top-down strategy has strong limitations and is highly dependent on the technology type, market structure and the nature and duration of the policy intervention [10]. Furthermore, it has been found that the decentralization of the innovation agenda and the active participation of end users in innovation processes can robustly boost the adoption of agricultural technologies [11], with further diffusion depending on the efficiency of the operating agricultural information systems [12].

According to Röling [12], agricultural information systems incorporate the three sub-systems of research, extension and utilization, where the active involvement of farmers is seen as determinant for the efficiency of the system's performance. Hippel [13] highlights the increasing ability of users to actively participate in the innovation process as rendering the processes of innovation design, diffusion and uptake more inclusive. Along these lines, the use of information and communication technologies (IT) by farmers are considered as instrumental for their empowerment in producing, storing and disseminating relevant agricultural information.

Aguilar-Gallegos et al. [14] point out that diversified and tailor-made extension strategies should be designed for the conditions of specific target groups. Radio programs and television shows, which have usually been approached from the top-down and organized by structured extension services, have historically formed the bulk of IT for agricultural extension in Mali [15]. However, social networks play an important role in the creation, as well as in the adoption, of innovation in agricultural contexts, with farm managers learning in informal processes within networks of colleagues and advisers [16]. This suggests that information transfer between peers: in this case between farmers, may be an effective approach to knowledge creation and/or dissemination. Furthermore, illiterate subsistence farmers in Mali may face special challenges in the organisation, storage, and communication of the created knowledge, which suggests the value of user operated IT systems to support them.

Methods for transferring information to farmers have been the focus of research for some time, but methods have to be suitable for the target groups [14], which suggests that methods can't just be copied from other places without consideration of context. Ramkumar [17] implemented a farmer-usable touch screen information kiosk in a veterinary institution, which helped cattle owners to treat their animals at an early stage of disease condition. Farmers in the U.K. were found to be informed by a relatively stable network of other communities of practice (or networks of practice), which Oreszczyn et al. [18] called a 'web of influencers on practice'. However these techniques may not be suitable in environments, such as in rural Mali, which have neither a developed web of influencers nor an institution that could host an information kiosk. Sulaiman et al. [19] argue that acknowledgement and integration of intermediaries, and their capacities for innovation, could enhance the potential of IT by ensuring that the information is provided in ways that enable communities to make use of it. Effective use of IT must be appropriate to rural realities, which, in much of rural Africa, is within the context of widespread illiteracy and sometimes limited, inefficient or even non-existent, extension services $[3,11]$.

A number of projects using IT have taken place in different rural areas around the globe to enable top down communication of content, although several of these require a degree of literacy. The African Cashew Initiative provided an IT based pricing and weighing system that can be used by farmers during the marketing season, with farmers being updated directly via their mobile phones [20]. The Lifelong Learning for Farmers program in Uganda provides an interactive SMS service with relevant agricultural information for farmers [21]. Mobile phones have been successfully used in Niger to communicate prices of agricultural products directly to farmers [22]. The iCow initiative in Kenya is a cloud based, centralized cattle management system, which has adopted the use of text 
messages and video [23]. These commendable initiatives however provide limited opportunity for farmer input, which in turn limits feelings of ownership by participating farmers.

Cai and Abbott [24] demonstrated that agricultural extension strategies can be complemented by the use of video in farmer training and that it can help overcome the gender and illiteracy barriers in information access. Digital Green in India produced videos and provided public screenings in villages to transfer information and enable exchange on best agricultural practices that can boost farm productivity and improve nutrition [25]. Farmer learning videos were found suitable to share high-quality information with large audiences in Bangladesh, although proper distribution is determinant for the success of the approach [26]. In the same country, Chowdhury et al. [27] concluded that agricultural extension is more effective with the use of facilitated video learning and that this approach is not only transferable across villages, but also works well in combination with other media, such as radio, television and mobile phones. Van Mele et al. [28] found that open-air video presentations facilitated unsupervised learning; unleashed local creativity and experimentation; and built confidence, trust, and group cohesion among rural people, including the poor, the youth, and women. More recently, Van Mele [29] reported video as an efficient tool to support south-south information transfer, with the advantage of providing a highly cost-effective opportunity to translate the information into any local language. In Mali, the use of learning videos has been demonstrated to increase knowledge and lead to the higher adoption of agricultural technologies [30, 31].

Although the use of video appears to be a promising means of information transfer, Sulaiman et al. [19] argued that information and communication technology based initiatives will be enhanced if they are embedded in a pragmatic world of communication and innovation process, which could be achieved when the power of distribution and intermediation of content lies with farmers. One way of placing control of content and distribution in the hands of farmers is to use IT systems that farmers already own, such as $3 \mathrm{G}$ phones [3].

Mobile phone enabled services are rising in demand including the use of videos - with benefits to smallholder farmers, although their potential remains poorly understood, particularly in the African context [32, 33, 34]. Videos on mobile phones have been effectively used to spread information on cowpea hermetic storage practices and other agricultural innovations in Niger [35]. Bentley et al. [15] cite farmers and local extension workers in Mali as having noted the promising potential of video on mobile phone and Bluetooth technology but that these technologies remain essentially unused in agricultural extension in Mali. In Burkina Faso, Maredia [36] compared the effectiveness of animated videos on mobile phone with the traditional extension approach of live demonstrations, to find out that there was no difference in the effectiveness of the two information transfer approaches in inducing learning and understanding of technologies that farmers were already aware of. After initially sharing farmer learning videos DVDs with 95 DJs in Malawi, a team of researchers was able to track 27 of those DJs one year later to find out that they had converted the agricultural videos to a format compatible with mobile phones in order to sell them to local farmers who had no DVD readers [37].

In recent years, third generation $(3 \mathrm{G})$ mobile phones, with video and Bluetooth capability, have become an important tool for communication in rural Africa [38, 39]. Rural Africa has experienced a particularly high uptake of information and communication technologies in the last 4 to 5 years [3] and the potential for short-term evolution of the used wireless communication technologies is predicted to advance at a fast pace in the next years [40]. Lawal-Adebowale [2] argues that mobile-phones are the most widely used IT device in Western African rural areas, with $62.9 \%$ of farmers in rural Nigeria owning such a device. Sousa et al [3] found that $92.5 \%$ of their sample of 400 farmers in Mali either owned, or had a family member who owned, a Bluetooth capable phone and all knew someone who possessed one, so had at least indirect access to $3 \mathrm{G}$ technology. Furthermore, Sousa et al. [3] found that Malians watch videos on mobile phones; mostly in groups and very frequently in public places of the village. These findings underline the potential of video use in $3 \mathrm{G}$ phones as a component of an agricultural extension strategy.

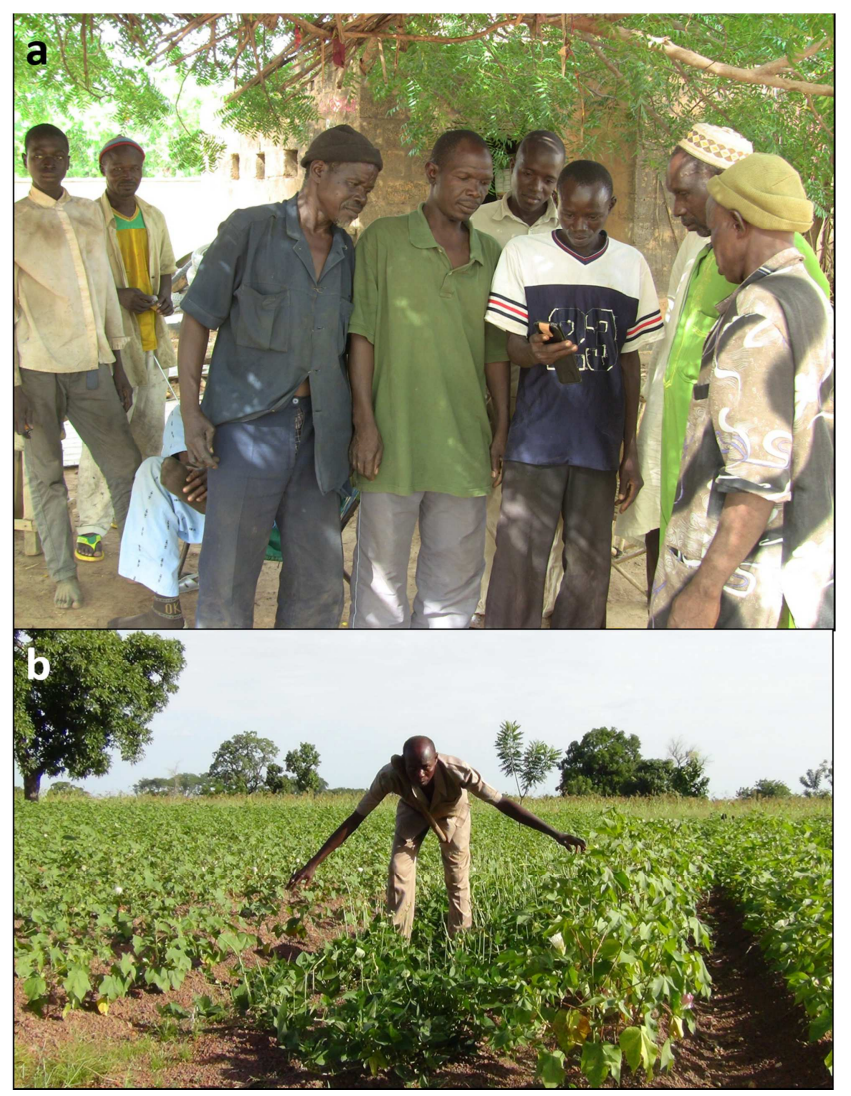

Figure 1. Farmers in the village of Touna, Mali, gather together to watch an agricultural learning video (a) and a cotton farmer points to the differences between the plot he fertilized using uniform application of compost, to the left, and the plot where compost was applied in pockets, to the right (b).

While this review of relevant literature was able to identify the potential of $3 \mathrm{G}$ phones as a means of general information 
transfer in rural West Africa, there is growing but little reported evidence of transfer of agricultural information via $3 \mathrm{G}$ mobile phones. The learning potential, which can be understood as the connection between information transfer and the implementation of innovation also remains understudied. Primary research is therefore needed to assess the impact that the already existing information and communication technologies have in the process of democratization of agricultural information systems. This knowledge gap is addressed by attempting to measure the extent to which mobile-phone videos are able to facilitate the diffusion of new agricultural technologies in West Africa.

\section{Methods}

Several videos were produced in 2013 as part of the dissemination strategy of a project called Syprobio (Systèmes de Production Biologiques). Syprobio was a EuropeAid funded project that aimed at promoting farmer led innovation in an organic farming context in Burkina Faso, Mali, and Benin. The videos were produced, in collaboration with local farmers who were encouraged to include their own messages, in a format that was easily comprehensible to farmers to portray different innovations that had been tested in Mali and neighboring Burkina Faso. Three of these videos were selected after pilot interviews had identified topics that were of particular interest to farmers in the Bla area of Mali. One video described the production and use of a bio-pesticide using Neem and hot pepper. Neem (Azadirachta indica) produces several of compounds known as limonoids, which have an antifeedant effect on insects and are therefore used in the formulation of many commercial biosinsecticides [41]. A second video compared three different ways of applying compost: uniformly, in rows, and in pockets. Research has shown that the application of compost and manure in pockets significantly increases yields and root development in cereal crops in the West-African Sahel [42], thus contributing to the sustainable intensification of African farming. A third video focused on intercropping cereals and legumes. Intercropping has repeatedly been shown to present different advantages, such as diversification of farm output, fixation of $\mathrm{N}$, more efficient pest management, and lower greenhouse gas emissions, being particularly beneficial for agricultural systems with low nitrogen availability [43]. The three videos were shown and shared with 200 farmers; using Bluetooth technology at no cost to the farmers, in September/October 2013. None of the 200 farmers were informed that there would be a second round of interviews after the initial contact. The same team returned to the area in July/August 2014, and was able to find 95 of the 200 farmers with whom the videos had been shared ten months earlier. This sample was supplemented by a further sample of 84 randomly selected farmers with whom the video had not been shared in the initial introduction of the videos. The final sample size was 179 farmers. Data were collected in face to face interviews in which farmers were asked whether they had seen the videos, whether and with whom they had shared the videos and whether they had implemented any of the three innovations shown in the videos.

The theoretical framework used in this analysis is the technology acceptance model [8], with the extension applied by Sousa et al. [3] to include control beliefs. The extended technology acceptance model suggests that new technologies will be adopted if they are perceived to be useful, perceived to be usable, and that the technology is available. Given the widespread availability of $3 \mathrm{G}$ phones, and the access to people with the technical skills to use them, the technology acceptance model suggests that the videos will be shared if they are perceived to be useful and usable. A second level, in this case, is whether technologies portrayed in videos will be adopted, and the same theoretical framework can be applied. The theory suggests that if the innovations are perceived to be useful and are perceived to be easy to use, they will be adopted. These theoretical considerations are expressed in practical terms as whether people have implemented the innovations contained in the videos.

\section{Results and Discussion}

\subsection{How Videos Were Shared and How They Spread}

From the farmers who received the videos in their mobile phone in September and October of $2013(\mathrm{~N}=95), 73$ shared the video via Bluetooth with other farmers (76.8\%) and 22 did not $(23.2 \%)$. The main reasons stated by those who did not share the video were: "lost the video before able to share" $(n=9)$; "other people already had the video" $(n=5)$; "other people saw it, but didn't ask for it" (n=7); and "no knowledge of Bluetooth" $(\mathrm{n}=22)$.

Those who did share the video via Bluetooth $(\mathrm{N}=73)$, shared it with a total of 431 farmers, to give an average share rate of 5.9 people per farmer. This rate is similar to that found by Baributsa et al. [35] in a study of farmers in Niger and their sharing a cowpea storage video. Although it is impossible to track how many shares happened in second degree, if a slightly lower share rate of 5 shares per farmer is assumed, the number of second-degree video users would rise to 2155. If an earlier saturation of the local social networks is considered, with 3 shares per farmer, the second degree video users would number around 1293 (figure 2).

Video transfer via Bluetooth is not the only way of describing the information flow, since videos are also visually shared with those who do not own a $3 \mathrm{G}$ phone. Farmers who received the video showed it to 9.9 other people on average, which is a higher number than the average share rate of video via Bluetooth. This result has implications for the real number of people who had access to the information. From the sample with whom the videos were not shared in $2013(\mathrm{~N}=84), 53(63 \%)$ had been shown the videos by other farmers. Our data supports the notion that the Bluetooth and visual sharing of videos by farmers can scale-up information in a self-propagative way; not only within villages but also to people outside of them. 


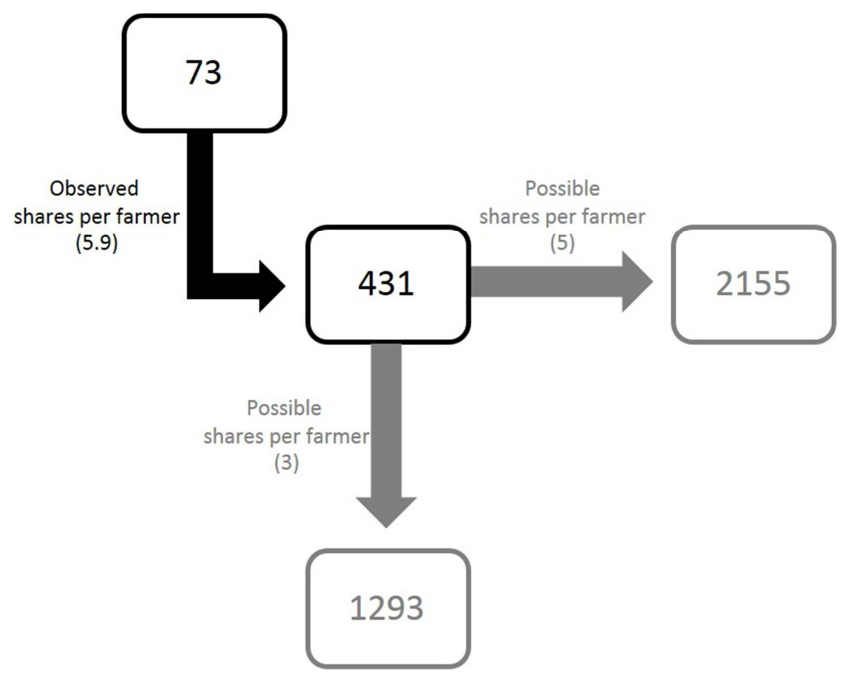

Figure 2. Video shares via Bluetooth: observed values (black) and estimated (grey).

The videos spread to other villages and towns according to the movements of farmers who initially received the video, as well as through contacts with visiting farmers from other places. The 73 farmers who received the videos said they transferred them via Bluetooth to farmers from 34 new villages. This brought the total of villages in which the videos were present from 12 to 46 in 10 months. On average, each farmer $(\mathrm{N}=73)$ transferred the videos to farmers from 1.99 villages, with a minimum of 1 and a maximum of 6 . Most of the new villages to which the videos were spread were located within $50 \mathrm{~km}$ of the center of the study area (Figure 3).

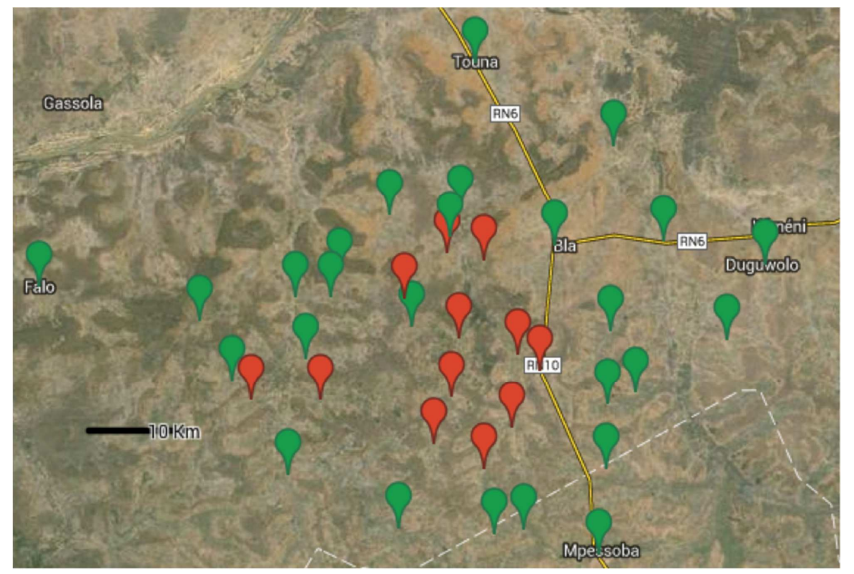

Figure 3. In red, the villages where the videos were initially shared in 2013, and in green, the villages where videos had been transferred via Bluetooth after 10 months.

The video transfer flowed more frequently to neighbouring villages, where contact with friends and family is more regular and likely. However, internal temporary migrations and other types of travel (family visits, ceremonies, trainings etc.), mean that some transfers occurred outside the $50 \mathrm{~km}$ range. Video presence was recorded in Kolokani (in the region of Bamako, $250 \mathrm{~km}$ northeast); Bledioni (in the region of Sikasso, $120 \mathrm{~km}$ south); Markala (in the region of Segou, $90 \mathrm{~km}$ north); and Tominian (in the area of San, $145 \mathrm{~km}$ east). It is impossible to know the full extent to which the videos were shared in Mali. Some farmers with whom the videos had been shared in 2013 were not present in their villages at the time of the last fieldwork. Furthermore, the extent to which second and third degree transfers took place cannot be measured.

\subsection{Rate of Video Innovation Uptake}

A further means of evaluating the reach and usefulness of the videos was to assess whether the videos had enabled innovations to be implemented. Farmers were considered to have implemented an innovation (enabled by the videos) if it was specifically stated that it was the first time they had applied the technique and that the video was the information source. An exception is the case of intercropping, which is an old practice that has fallen out of use. Farmers were considered have implemented this innovation (enabled by the videos) when they stated having been explicitly motivated by the video to apply this technique.

Of the farmers who had watched the video $(\mathrm{N}=148), 89$ $(60 \%)$ had applied at least one of the videos' innovations; 46 (31\%) had not applied any of the innovations; and 13 (8.8\%) of the farmers either didn't know or didn't answer. The innovation with the highest implementation rate was the 'compost application technique', which was implemented by 74 of the $89(83 \%)$ farmers. Despite the video referring to cotton, many farmers applied this technique to other crops, such as maize, sorghum, millet, okra and watermelon. The higher rate of implementation seems to be related mainly to the perception by farmers that compost is a scarce resource and must be maximized to improve productivity. For the farmers who adopted the innovation, it was important to see the results in the video and to hear the testimonies of farmers talking about their results. Many applied the compost in pockets or in lines, as was suggested in the video. The farmers reported that their main limitation was the availability of workers. All of the farmers who had implemented the innovation had previously, before watching the video, applied compost to their fields in a uniform way.

The 'intercropping' innovation was applied by 14 (15.7\%) farmers. The most commonly used varieties were maize, sorghum and cowpeas, which were the crops shown in the video. Some farmers included sesame and cotton in the mix. Two farmers applied both compost application techniques and intercropping. The third video provided information about a biopesticide using Cassia nigricans and hot pepper, which had been tested in Burkina Faso. This innovation was hardly applied since Cassia nigricans is not used in the area, and the most widely used biopesticide is based on neem seeds. The implementation rate of the agricultural innovations shown in the three videos is summarized as in table 1 . 
Table 1. Summary table describing innovation implementation rates.

\begin{tabular}{llll}
\hline Innovation & $\mathbf{N}$ & $\mathbf{\%}$ & Observations \\
\hline Compost application techniques & 74 & 83 & Farmers applied compost in pockets or in lines instead of uniformly as they used to \\
Intercropping & 14 & 15.7 & Farmers restarted mixing crops or did it for the first time with the mix suggested in the video \\
Biopesticide (Cassia+pepper) & 1 & 1 & Cassia is unknown in the area \\
Total & 89 & 100 & \\
\hline
\end{tabular}

\section{Conclusions}

As demonstrated by a previous study of the same research team [3], farmers in the rural areas of Mali have ready access to third generation $(3 \mathrm{G})$ mobile phones, as well as the skills to use them, and they perceive them as having potential for use as an agricultural information tool that would be beneficial to them. The technology acceptance model requires that these three conditions be met in order to consider a technology as having potential to be adopted. In the light of this explanatory framework, the results of this study support $3 \mathrm{G}$ phone technology as having a strong potential as a means of farmer-to-farmer information transfer, since it was widely used by farmers to share the innovations portrayed in the videos, with some being implemented in their fields. Some caution should however be taken in interpreting these results. The videos were distributed, and the implementation of the innovations was assessed, but it was beyond the scope of this study to control against external influencing factors. Although this is regarded as an unlikely coincidence, it cannot be completely ruled out that the implemented innovations may have been motivated by another source other than the videos. Directly asking the interviewed farmers whether the motivation came from the videos is furthermore susceptible to socially desirable response bias. Despite this limitation, some conclusions can be drawn.

The results of this study reinforce the proposal that videos can play an important role in enabling farmers to implement innovative practices. This shows that video based diffusion strategies can increase the adoption rates of agricultural practices by a factor of six to seven times the classical, person-only, agricultural extension. The use of videos was shown to create a horizontal platform of information exchange among the rural population, relying on farmers' own personal contacts and being independent from the typically top-down information transfer from extension structures or pure video or radio transmissions. The participatory production of videos for mobile phones; involving farmers and their own messages, could further enhance the dissemination and implementation of innovations because of the trust among peers who share similar circumstances and problems, and the same vernacular language.

Widespread illiteracy is recognized as a major constraint in the process of dissemination and implementation of agricultural innovations in most of Western Africa's rural areas. Videos on mobile phones provide an opportunity to overcome this obstacle, allowing the production of messages that can be easily understood by farmers and easily translated to local vernacular languages. This type of information exchange can greatly amplify agricultural extension efforts and prevent the exclusion of specific groups, such as women and younger farmers. Furthermore, the self-propagative characteristics of this technology could lower extension efforts while increasing the rates of dissemination and adoption of agricultural innovations.

The implementation of the compost application technique in rows, as opposed to uniformly, was by far the most popular innovation; answering to some of the farmers' main concerns such as crop productivity and low soil fertility. The crosscutting characteristics of this information transfer were demonstrated in that the technique was implemented not only with cotton, as portrayed in the video, but also in other crops grown by farmers. This flexibility in the implementation of the acquired knowledge implies that more accessible information transfer tools can have a deep impact in a rural society that is eager to access new agriculturally related information; further adapting it to its needs. This communication strategy ultimately enables, in an unprecedented way, farmers to become the owners of relevant and easily shareable information, which can then be adapted to their needs. It is concluded that a communication strategy involving videos on mobile phones can contribute to make agricultural information systems more democratic and may increase the rates of dissemination and implementation of agricultural innovations: particularly in the rural areas of the developing world.

\section{Acknowledgements}

This study was conducted in the area of Bla, Mali. We would like to thank UNPCB, MOBIOM, CRRA-IER and INERA. Special thanks go to the following members of the Syprobio project team: Rémy Dabire, Laurent Glin, Fagaye Sissoko, Kouka Yameogo, Odiaba Samake, Andreas Fliessbach, Karim Coulibaly and Daouda Konaté. We are especially grateful to all farmers involved in the study in Mali and Burkina Faso who freely gave their time. The work was financially supported by EuropeAid: the funding agency of Syprobio.

\section{References}

[1] Syiem R., Raj S. (2015). Access and usage of ICTs for agriculture and rural development by the tribal farmers in Meghalaya state of north-east India. Journal of Agricultural informatics. 6(3):24-41. doi:10.17700/jai.2015.6.3.190. 
[2] Lawal-Adebowale A. (2012). ICT in Agricultural Development: Its Diffusion and Adoption Pattern in Nigeria's Agricultural System. In Maumbe B., and Patrikakis C. (eds) E-Agriculture and Rural Development: Global Innovations and Future Prospects. IGI Global, USA.

[3] Sousa F., Nicolay G., Home R. (2016). Information technologies as a tool for agricultural extension and farmer-tofarmer exchange: Mobile-phone video use in Mali and Burkina Faso. Int $\mathbf{J}$ Educ Dev Using Inf Commun Technol. 12(3):19-36.

[4] UN (United Nations Economic Commission for Africa) (1998). ICTs as tools of democratization: summary. UN-ECA African Women and Economic Development. http://hdl.handle.net/10855/4102. Site visited March 5, 2018.

[5] Tey S., Li E., Bruwer J., Abdullah M., Brindal M., Radam A., Ismail M. and Darham S. (2017). Factors influencing the adoption of sustainable agricultural practices in developing countries: A review. Environ Eng Manag J. 16(2):337-349.

[6] Rogers E. M. (2003). Diffusion of Innovations, 5th Edition, New York, Free Press.

[7] Ghadim A., Panell D. (1999). A conceptual framework of adoption of an agricultural innovation. Agricultural economics $21: 145-154$

[8] Davis D. (1989). Perceived usefulness, perceived ease of use, and user acceptance of information technology. Manag Inf Syst Q. 13(3):319-339. doi.org/10.2307/249008.

[9] Kiptot E., Hebinck P., Franzel S., and Richards P. (2007). Adopters, testers or pseudo-adopters? Dynamics of the use of improved tree fallows by farmers in western Kenya. Agr Syst. 94:509-519. doi.org/10.1016/j.agsy.2007.01.002.

[10] Feder G., Umali D. (1993). The adoption of agricultural innovations: A review. Technological forecasting and social change 43(3-4):215-239 https://doi.org/10.1016/00401625(93)90053-A.

[11] Pamuk H., Bulte E., and Adekunle A. (2014). Do decentralized innovation systems promote agricultural technology adoption? Experimental evidence from Africa. Food Policy 44:227-236.

[12] Röling N. (1988). Extension science: Information systems in agricultural development. Cambridge University Press, Cambridge, UK.

[13] Hippel E. (2005). Democratizing Innovation. MIT Press, London.

[14] Aguilar-Gallegos N., Muñoz-Rodríguez M., Santoyo-Cortés H., Aguilar-Avila J., and Klerkx L. (2015). Information networks that generate economic value: A study on clusters of adopters of new or improved technologies and practices among oil palm growers in Mexico. Agr Syst. 135:122-132. doi.org/10.1016/j.agsy.2015.01.003.

[15] Bentley J., Van Mele P., Zoundji G., and Guindo S. (2014). Social innovations triggered by videos: Evidence from Mali. Agro-Insight Publications.

http://agroinsight.com/downloads/Articles-AgriculturalExtension/2014_Social-innovations-triggered-by-videos-inMali-Bentley-et-al-2014.pdf. Site visited March 5, 2018.

[16] Gielen M., Hoeve A., and Nieuwenhuis M. (2003). Learning Entrepreneurs: learning and innovation in small companies. European Educational Research Journal 2(3): 90-106. doi.org/10.2304/eerj.2003.2.1.13.

[17] Ramkumar S., Garforth C., Rao N., and Heffernan C. (2007). Design and Formative Evaluation of an Information Kiosk on Cattle Health for Landless Cattle Owners. J Agr Educ Ext. 13:7-22. doi.org/10.1080/13892240601162007.

[18] Oreszczyn S., Lane A., and Carr S. (2010). The role of networks of practice and webs of influencers on farmers' engagement with and learning about agricultural innovations. J Rural Stud. 26:404-417. doi.org/10.1016/j.jrurstud.2010.03.003.

[19] Sulaiman R., Hall A., Kalaivani J., Dorai K., and Reddy V. (2012). Necessary, But Not Sufficient: Critiquing the Role of Information and Communication Technology in Putting Knowledge into Use. J Agr Educ Ext. 18:331-346. doi/abs/10.1080/1389224X.2012.691782.

[20] Kachelriess-Matthess S., Keller P., Orleans C., Agbo B., Baro Y., Frankel S., Shantz J., and Huelss J. (2011). Using SMS Messages to Enhance Services of a Farmers' Union to its Members.

http://africancashewinitiative.org/imglib/downloads/120328_s ms_text_messages_ab.pdf. Site visited March 5, 2018.

[21] SIANI (Swedish International Agricultural Network Initiative) (2012). From motorbike to mobile phone: new extension services for rural farmers through mobile ICT - Discussion brief. https://www.seiinternational.org/mediamanager/documents/Publications/SEIDiscussionBrief-SIANI-ICTandAfricanFarmers-2012.pdf. Site visited March 5, 2018

[22] Aker J. (2008). Does Digital Divide or Provide? The Impact of Cell Phones on Grain Markets in Niger. Center for Global Development, Working Paper 154.

http://www.oecd.org/countries/niger/41713177.pdf. Site visited March 5, 2018.

[23] Kshetri N. (2013). Cloud Computing in Sub-Saharan Africa. IT Professional. 15(6):64 - 67. doi:ieeecomputersociety.org/10.1109/MITP.2013.92.

[24] Cai T., Abbott E. (2013). Using Video as a Replacement or Complement for the Traditional Lecture/ Demonstration Method in Agricultural Training in Rural Uganda. J Appl Commun Res. 97(4):47-61. doi.org/10.4148/1051-0834.1127.

[25] Gandhi R., Veeraraghavan R., Toyama K., and Ramprasad V. (2009). Digital green: Participatory video for agricultural extension. Proceedings of International Conference on Information and Communication Technologies and Development. doi.org/10.1109/ICTD.2007.4937388.

[26] Bentley J. W., Van Mele P., Harun-Ar-Rashid M., and Krupnik T. J. (2015). Distributing and Showing Farmer Learning Videos in Bangladesh. Journal of Agricultural Education \& Extension 22(2):179-197.

[27] Chowdhury A., Odame H. H., Thompson S., and Hauser M. (2015). Enhancing farmers' capacity for botanical pesticide innovation through video-mediated learning in Bangladesh. International Journal of Agricultural Sustainability 13(4):326-349.

[28] Van Mele P., Wanvoeke J., Zossou E. (2010). Enhancing rural learning, linkages, and institutions: The rice videos in Africa. Dev Pract. 20:414-421. 
[29] Van Mele P., Okry F., Wanvoeke J., Barres N., Malone P., Rodgers J., Rahman E., Salahuddin A. (2018). Quality farmer training videos to support South-South learning. CSI Transactions on IT 6(3-4):245-255.

[30] Zoundji G.C., Okry F., Vodouhê, S.D. and Bentley J.W. (2018a). Towards sustainable vegetable growing with farmer learning videos in Benin. International Journal of Agricultural Sustainability 16(1), 54-63.

[31] Zoundji G.C., Okry F., Vodouhê, S.D., Bentley J.W. and Tossou R.C. (2018b). Beyond Striga management: Learning videos enhanced farmers' knowledge on climate-smart agriculture beyond Striga management. Sustainable Agriculture Research 7(1), 80-91.

[32] Semeon G., Garfield M., and Meshesha M. (2015). Towards Enabling Tacit Knowledge Externalization Using Mobile Phone: The Case of Participatory Agricultural Innovation in Ethiopia. Proceedings of the 2015 12th Ieee Africon International Conference - Green Innovation for African Renaissance (africon) Ieee, New York.

[33] Duncombe R. (2016). Mobile Phones for Agricultural and Rural Development: A Literature Review and Suggestions for Future Research. The European Journal of Development Research 28(2):213-235.

[34] Baumueller H. (2018). The Little We Know: An Exploratory Literature Review on the Utility of Mobile Phone-Enabled Services for Smallholder Farmers. Journal of International Development 30(1):134-154.

[35] Baributsa D., Lowenberg-DeBoer J., and Kamarou Djibo A. (2010). Cell phone video for communicating hermetic cowpea storage skills. 5th World Cowpea Research Conference. Dakar, Senegal. https://ag.purdue.edu/ipia/pics/Documents/Research Papers/Cellphone Paper- Baributsa-LowenbergDeBoer and Djibo Nov 262010 Final.pdf. Site visited March 5, 2018.

[36] Maredia M. K., Reyes B., Ba M. N., Dabire C. L., Pittendrigh B., and Bello-Bravo J. (2018). Can mobile phone-based animated videos induce learning and technology adoption among low-literate farmers? A field experiment in Burkina Faso. Information Technology for Development 24(3):429 460.

[37] Bentley J., Udedi R., Van Mele P. (2016). Malawi DJs distribute videos to farmers. Access Agriculture Report, Nairobi: http://agroinsight.com/downloads/Articles-Agricultural-

Extension/2016_AE_Malawi-DJs-distribute-videos-to-farmersBentley-et-al-2016.pdf.

[38] Simba Y., Zaipuna O. (2014). ICT as a Tool For Improving Information Flow Among Livestock Stakeholders. A Case Study of Tanzania. International Journal of Computer Science and Information Security. 12(8):414-424.

[39] Mwombe S., Mugivane F., Adolwa I., and Nderitu J. (2013). Evaluation of Information and Communication Technology Utilization by Small Holder Banana Farmers in Gatanga District, Kenya. J Agr Educ Ext. 20(2):247-261. doi.org/10.1080/1389224X.2013.788454

[40] Aggarwal R. (2018). Wireless communication: Evolution and advance wireless communication. CSI Transactions on IT $4(2): 25-30$.

[41] Zuleta-Castro C., Rios D., Hoyos R., and Orozco-Sanchez F. (2017). First formulation of a botanical active substance extracted from neem cell culture for controlling the armyworm. Agron Sustain Dev. 37:40. doi.org/10.1007/s13593-017-0448-4.

[42] Aune J. B., Coulibaly A., and Giller K. (2017). Precision farming for increased land and labour productivity in semiarid West Africa. A review. Agron Sustain Dev. 37:16. doi.org/10.1007/s13593-017-0424-Z.

[43] Bedoussac L., Journet E. P., Hauggaard-Nielsen H. Naudin C., Corre-Hellou G., Jensen E., Prieur L, and Justes E. (2015). Ecological principles underlying the increase of productivity achieved by cereal-grain legume intercrops in organic farming. A review. Agron Sustain Dev. 35:911. doi.org/10.1007/s13593-014-0277-7. 